\title{
Ergonomics of bridge employment
}

\author{
Mokdad Mohamed \\ Department of Psychology, College of Arts, Bahrain University, P.O. Box 43038 Sakhir, Bahrain
}

\begin{abstract}
In many countries of the world, retirement is mandatory at the age at which persons who hold certain jobs or offices are required by employment law to leave their employment, or retire (60 to 65 years). Typically, this is justified by the argument that certain occupations are either too dangerous or require high levels of physical skills and mental work. Every worker has to leave the workforce at that age. However, starting from the last two decades of the last century, it is observed that retirees live more years in retirement than ever before. This relatively long retirement as well as retirees' body fitness made many of them engage in new jobs which are either similar to their career jobs, or completely different from them. In this new type of employment which is called "bridge employment", the retired worker may spend more than ten years. But, to what extent these new jobs are fitted to the aged worker? Considering that experiencing any type of event increases the risk of worse health outcomes over time, bridge employment should be ergonomically designed if it is to fit the aged worker characteristics (physical, mental and affective).
\end{abstract}

Keywords: retirement, aged worker, career jobs, bridge employment, ergonomics

\section{Introduction}

Previously, a small number of old workers would have both the ability and the willingness to start a new work after retirement. The physical fitness of workers and work (work content and environment) were behind this situation. However, starting from the last two decades of the last century, many retirees would have started some form of work for some more years.. It is called bridge employment. Bridge employment refers to the work an individual takes up after retirement from career work. It is called bridge employment because it bridges between first retirement and final retirement (stopping completely the work). Quinn defined bridge employment as a parttime or short-duration job that occurs between fulltime career employment and complete labor force withdrawal [1]. It acts as a transition between longterm career positions and total retirement (Figure 1).

The number of people doing this work is increasing. But to what extent is it fitted to those who are doing it?

Studying ergonomically this work is the responsibility of ergonomists. Since the 1997 International Ergonomics Association congress that was held in Tampere, (Finland), a lot of international concern over the aging of the workforce has been there to demonstrate the interest in issues related to the older worker. This international concern may be motivated to a certain extent by the large number of bridge employment workers in the workplace. There is growing evidence to suggest that universally there has been a significant increase in the number of bridge employment workers in a diversity of jobs. Winn and Ilmarinen predict the working population over 50 years of age will explode during the next 25 years, and argue that the work force will soon comprise approximately $35 \%$ of bridge employment workers $(50-64$ years $)$ and only $17 \%$ of younger workers $(15$ -24 years) [2]. The large number of bridge employment workers at work especially in developed countries, is attributed to the fact that the elderly population of today is on average healthier, better educated, and wealthier than the elderly population of previous generations.

Despite the fact that ergonomists have studied just about all types of employment, bridge employment has been left unstudied. This situation could be attributed to the fact that, it is a new phenomenon in the world of work.

\footnotetext{
*E-mail: mokdad@hotmail.com
} 


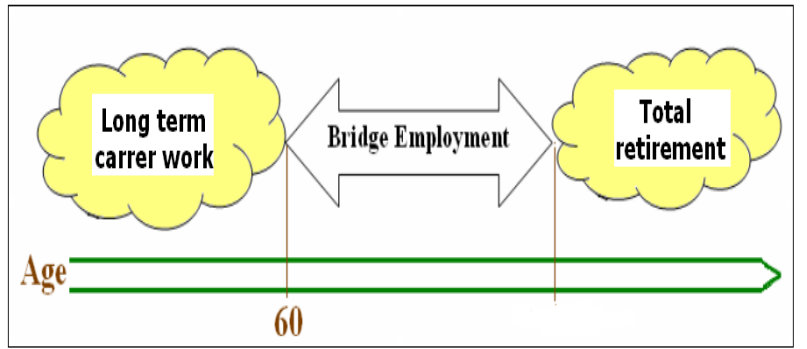

Fig.1: career work, bridge employment and total retirement

In this paper, some light will be shed on this kind of employment, and on how it is ergonomically designed, mainly answering the following questions:

i. Why to engage in bridge employment?

ii. What types of bridge employment prevail in both developed and developing countries?

iii. What are the effects of bridge employment?

iv. How to design to fit the older worker?

\section{Method}

The type of methodology I will be using will be a descriptive investigation through literature review and analysis. The aim was to synthesize, with commentary, the significant body of information that is available on bridge employment. Two sub-types of literature review were considered. These are:

a) The historical review which traces the development of bridge employment concept in the last two decades. b) And, the integrative review that summarizes the amount of information about bridge employment and how ergonomics can help make this employment less physically demanding and more efficient.

To accomplish these reviews, various data bases were consulted. The Most widely used ones were ERIC, PsycINFO and ScienceDirect.

\section{Results and Discussion}

\subsection{Why to engage in bridge employment?}

Several studies have been conducted $[3,4]$, to answer this question. They found that financial pressure and good health status were two important motivators for retirees to participate in bridge employment, with financial pressure making retirees feel that they should engage in bridge employment and good health status providing the capacity for them to engage in bridge employment. According to Kendrick, the factors that may push retired workers to start a bridge employment are complex, and may be classified as personal or environmental factors. Personal factors include overall life satisfaction, certainty of retirement plans, career-related pull factors, satisfaction with pre-retirement work, job satisfaction, personal choice, fulfillment of the need of intellectual challenge, and companionship. However, Environmental factors include economic stability, salary at time of retirement, health, age, presence/absence of working spouse, dependent children, organizational tenure, and job tenure [5].

Table 1

Distribution of bridge employment workers according to types of bridge employment

\begin{tabular}{|l|l|l|}
\hline Bridge employment type & Developed countries & Developing countries \\
\hline Full Time Reemployment & $\sim 10 \%$ & $\sim 05 \%$ \\
\hline Part time employment & $\sim 60 \%$ & $\sim 20 \%$ \\
\hline Self employment & $\sim 30 \%$ & $\sim 70 \%$ \\
\hline
\end{tabular}

\subsection{What are the types of bridge employment? And what is prevailing in both developed and developing countries?}

The major types of bridge employment are fulltime re-employment, part-time work, and selfemployment.

Full-time re-employment is employment in which the old employee works the full number of hours defined as such by his/ her employer. Full-time re- employment often comes with benefits that are not typically offered to part-time workers, such as annual leave, sick-leave, and health insurance.

Part-time employment is a form of employment that carries fewer hours per week than a full-time job. Workers are considered to be part-time if they commonly work fewer than 30 or 35 hours per week. Part-time employment may take many forms, of which are Job sharing and phased retirement. Job sharing is an employment arrangement where typically two people are retained on a part-time or re- 
ly two people are retained on a part-time or reducedtime basis to perform a job normally fulfilled by one person working full-time. Phased retirement is a special form of part-time work designed for bridge employment workers. It includes any human resources program that allows workers to reduce their work hours without changing employers and eases the transition into retirement.

Self-employment is working for one's self. The self-employed can be a person who works for himself/ herself instead of an employer, but drawing income from a trade or business that they operate personally.

The distribution of bridge employment workers in both developed and developing countries according to these three types is seen in table 1.

It can be seen from Table 1 that distribution of bridge employment workers trends are different. In developed countries where there are presently some manpower shortages, the proportion of bridge employment workers doing full- reemployment is large. On the other hand, a small proportion is seen in self employment. As to the developing countries, and because unemployment is higher, and a lot of stress is put on governments to find jobs for the unemployed, no chances are given to the retired to rejoin the workforce after the standard retirement. Therefore, a very small proportion $(\sim 05 \%)$ of retired workers is engaged in bridge employment. In the same line, about $20 \%$ only are found in part time employment. The majority of retired workers are doing some kind of self-employment mainly in agricultural work and craft activities.

\subsection{What sort of effects does bridge employment have?}

Bridge employment does seem to have positive effects on workers. Zhan, et al [6] found that engaging in bridge employment either in a career field or in a different field was associated with fewer major diseases and functional limitations, whereas engaging in career bridge employment was associated with better mental health. In addition, Bosse, et al., [7] and Bosse, et al. [8] have shown that full retirees report more psychological symptoms than do bridge employment workers doing bridge employment. These findings seem to highlight the health benefits of engaging in bridge employment for retirees. Specifically, choosing a suitable type of bridge employment as a transition strategy is likely to lead to beneficial effects on retirees' physical and mental health conditions. The positive effects of bridge employment on older worker can be attributed to two major factors; the nature of bridge employment and what bridge employment causes. As to the nature of bridge employment, it is often the choice of the older worker. In addition, it is a paced work carried out usually on part-time basis. As to what bridge employment causes, it keeps the older worker busy, having social relations with peers, and a source for financial aid.

\subsection{How to design bridge employment to fit the older worker?}

To design bridge employment to fit the older worker, the following four-step protocol should be used:

1) Identify the physical, physiological and psychological demands of the job: To identify the physical, physiological and psychological demands of the job, It is necessary to carry out a job analysis which is the systematic process for collecting data about work activities, equipment, context, and job specifications (knowledge, skills, abilities and other things such as interests (KSAOs)) required of the job. Job analysis identifies the KSAOs necessary for job success and provides criteria for successful performance.

2) Identify the physical, physiological and psychological capabilities of the older worker: As we age, we inevitably change in many ways. As far as bridge employment is concerned, the changes that occur to the physical, physiological and psychosocial capacities of aging employees should be considered.

2.1) Physical capabilities: At the age of 65 years, 25 to 30 percent decrease in strength. According to Hettinger [9] at the age of 65 we have about $70 \%$ of the strength that we had at our youthful peak from 25 to 30 . Also, all sight aspects deteriorate. The ability of our eyes to focus on objects (accommodation) declines. This is due to the loss of elasticity in the lens of the eye. Furthermore, approximately onethird of 65-74 year old people have hearing problems mainly hearing loss. Besides, at old age, motor skills (manual dexterity and tactile feedback) deteriorate, and reaction time decreases.

2.2) Physiological capabilities: At the age of 65 years old, 40 percent decrease in oxygen exchange, 25 percent less in respiratory system, 15-20 percent less in cardiovascular system, and systemic blood pressure increases $[10,11]$. One of the major results of these changes is that fatigue occurs more rapidly.

2.3) Psychological capabilities: Cognitive changes also occur among aging adults. It may take 
older adults more time to encode, store, and retrieve information. The rate, at which new information is learned by them, can be slower. Long-term memory shows substantial changes with age, while short-term memory shows less age-related decline. In addition, most aspects of language ability remain strong. However, wisdom and creativity often continue to the very end of life. Overall prevalence of mental disorders in older adults is less than in any other age group $[12,13]$.

3) Recognize the mismatches between the demands and the capabilities: There is no doubt that if mismatch exists in the work place, it can be perceived through observational and evaluative criteria. Observational methods include: observation, psychological measures, interviews, and questionnaires. And evaluative criteria include: low quality and quantity products, large amount of money spent at work, and repeated absenteeism.

4) Minimize the mismatches between the demands and the capabilities through ergonomics and vocational harmonization:

4.1) Minimization through Ergonomics: The major goal of ergonomics is to fit the job to the worker. In addition, its other goals are: to design workplaces, equipment, and work environment, to remove risk factors and obstacles that hinder optimum performance in order to prevent injuries, illnesses, and errors and to improve overall employee wellness and overall business performance. To design the workplace for the older worker, ergonomics considers the following parameters:

- Physical limitations: With the physical limitations (visual, hearing and motor) that naturally come with age, we can expect that many old workers would be prevented from doing easily bridge work. Therefore, any workplace modifications that serve to overcome physical limitations are beneficial to bridge workers, and will accommodate the older worker into the workplace.

- Environmental limitations: Due to age effects, the elderly capabilities to beat harsh physical environment effects (noisy environment, poor workplace lighting, heat and cold stress, etc,,,) decline. Therefore, employers should consider these changes while recruiting the retired worker for bridge employment. Studies have shown that well-designed environments (adequate lighting, well conditioned work places, comfortable and accessible furnishings, and spaces that allow ease of movement, etc,,,) can, reduce anxiety, lower blood pressure, and increase job satisfaction [14]. Workers have been found to walk more efficiently (have greater step length, speed) and feel more secure and confident on carpeted, compared to vinyl, surfaces [15]. Conversely, research has linked poor design of surroundings, to negative effects such as higher occurrence of restlessness, elevated depression, and anxiety $[16,17]$.

- Implementing Job design Measures: For bridge employment workers, job design measures such as job rotation and enlargement serve to reduce general fatigue and the accumulation of stressors on particular body parts. It is therefore, essential to analyze the physical stressors that predominate in each job and then rotate or enlarge on the duties of the job in order to diffuse job stressors. Furthermore, bridge employment workers are not particularly adaptable to night or shift work as are younger workers. This is due to the fact that they are frequently prone to sleeping disturbances and are less resistant to the stresses that characterize night shifts. It is consequently recommended that the older worker be given the choice of earlier shifts if possible.

4.2) Minimization through Vocational harmonization: The major goal of vocational harmonization is to fit the worker to the job. In addition, its other goals are: to increase the workers' ability and willingness to do the work. Ergonomics and vocational harmonization have been complementing each other since the emergence of ergonomics after Second World War. At any time possible, if both fields are practiced, it is preferable to begin with implementing ergonomic interventions. Once ergonomic interventions have been done, then vocational harmonization functions follow. The most widely used vocational harmonization functions are workers recruitment and training $[18,19]$. Rynes, [20] defines recruitment as follows: "Recruitment encompasses all organizational practices and decisions that affect either the number, or types, of individuals who are willing to apply for, or to accept, a given vacancy". And Tsang, [21] defines vocational training as any type of job-related learning that raises an individual's productivity, and includes learning in formal vocational and technical school programs in training centers or institutes, and in the workplace, both on and off the job. The importance of both the recruitment and training functions is clear when one realizes that by hiring the most competent applicants and training them, the firm's performance can be significantly enhanced. Vocational harmonization functions do not cover up only job related skills, but also the health aspects of the older worker. In this standpoint, Shephard, [22] showed that employee wellness programs benefit older employee aspects such as aerobic power, thermoregulation, Selfefficacy and mood-state and healthy lifestyle. He 
mentioned that these programs will accommodate and sustain the effectiveness of older employees. Also, he believes that the productivity of older employees in technologically advanced work can be sustained by appropriately adapted programs for the up-grading of skills and the acquisition of new knowledge. Furthermore, It has been mentioned that the ability of older people to learn is similar to that of the young people. Studies on aging have demonstrated that learning ability does not decline with age. If older people remain healthy, their intellectual abilities and skills do not decline [23, 24]. Therefore, age is not necessarily a barrier to learning and that older people have a wealth of experiences that they can bring into a new learning experience.

\section{Conclusion}

Even though a good amount of research on ergonomics of the elderly has been done $[25,26,22,1,27$, $28,29]$, ergonomic research on the ramifications of bridge employment on bridge employment workers has been quite lacking. This can be attributed to the fact that bridge employment is a new phenomenon in the domain of work. And it has been found to be a work of positive effects on workers.

What sort of ergonomics is needed for bridge employment? There are many types of ergonomics. If the nature of job aspects is taken as a basis for classification, two types of ergonomics come to the façade, which are therapeutic and preventive ergonomics. Therapeutic ergonomics considers the negative aspects of the job hoping to improve the workplace, equipment and environment so that the older worker does his/ her job efficiently and safely. Preventive ergonomics considers how to strengthen the jobs where workers feel satisfied and motivated to do the job. Bridge employment that is seen in both developed and developing countries, seems to need the practice of more preventive ergonomics than therapeutic ergonomics.

\section{References}

[1] Quinn, J. (2002). Changing retirement trends and their impact on elderly entitlement programs. In S. Altman \& D. Schactman (Eds.), Policies of an aging society (p. 295). Baltimore, MD: The John Hopkins University Press.

[2] Winn, F.J, and Ilmarinen, J. (2000). An international perspective on the older worker. International Journal of Industrial Ergonomics, 25(5), 461-463.
[3] Wang, M., Zhan, Y., Liu, S., \& Shultz, K. S. (2008). Antecedents of bridge employment: A longitudinal investigation. Journal of Applied Psychology, 93, 818-830.

[4] Weckerle, J. R., \& Shultz, K. S. (1999). Influences on the bridge employment decision among older U.S.A. workers. Journal of Occupational and Organizational Psychology, 72, 317-330.

[5] Kendrick. S.K. (2007). Bridge Employment: Making the Connection with Pre-Retirees' Needs, Wants, and Goals. Ph.D. Dissertation Presented to the Faculty of the College of Business Administration of Touro University International.

[6] Zhan, Y.; Wang, M.; Liu, S. and Shultz, K. S. (2009). Bridge Employment and Retirees' Health: A Longitudinal Investigation. Journal of Occupational Health Psychology, 14(4), 374 389.

[7] Bosse, R., Aldwin, C. M., Levenson, M. R., and Ekerdt, D. J. (1987). Mental health differences among retirees and workers: Findings from the normative aging study. Psychology and $\mathrm{Ag}$ ing, 2, 383-389.

[8] Bosse, R., Workman-Daniels, K., Aldwin, C. M., Levenson, M. R., and Ekerdt, D. J. (1990). Differences in social support among retirees and workers: Findings from the Normative Aging Study. Psychology and Aging, 5, 41- 47.

[9] Hettinger, T. (1960). Muskelkraft bei Mannern und Fraun. Zentralblatt Arbeit und Wissenschaft, 14, 79-84

[10] Ogawa, T., Spina, R.J., Martin, W. H. Kohrt, W. M. Schechtman, K. B., Holloszy, J.O, and Ali Ehsani, A.A. (1992). Effects of Aging, Sex, and Physical Training on Cardiovascular Responses to Exercise. Circulation, 86, (2), 494-503.

[11]Buskirk, E.R, and Hodgson, J.L (1987). Age and aerobic power: The rate of change in men and women. Fed Proc (Federation proceedings), 46, 1824-1829.

[12] Anstey, K. J. and Low, L.F. (2004). Normal cognitive changes in aging. Australian Family Physician, 33, (10), 783- 787.

[13] Christensen, H. (2001). What cognitive changes can be expected with normal aging? Australian and New Zealand Journal of Psychiatry, 35, 768-775.

[14] Parsons, K.C. (2000). Environmental ergonomics: a review of principles, methods and models. Applied Ergonomics, 31, 581594.

[15] Willmott, M. (1986). The effect of vinyl floor surface and a carpeted floor surface upon walking in elderly hospital patients. Age and Ageing, 15, 119- 120.

[16]Ulrich, R. S. (1991). Effects of health facility interior design on wellness: Theory and recent scientific research. Journal of Health Care Design, 3, 97-109.

[17]Ulrich, R. S. (1992). How design impacts wellness. Healthcare Forum Journal, 20, 20-25.

[18] Aamodt, M.G. (1996) Applied industrial $\backslash$ organizational psychology. Pacific Grove, CA: Books $\backslash$ Cole.

[19]Dessler, G. (1995). Personnel human resource management. Englewood cliffs, NJ Prentice Hall.

[20]Rynes, S.L., (1990). Recruitment, job choice, and post hire consequences: a call for new research directions. In Dunnette, M. and Hough, L.M., Handbook of Industrial and Organizational Psychology, Vol. 2, Consulting Psychology Press, Palo Alto, CA.

[21]Tsang, M.C. (1999). The cost of vocational training. Education and Training, 41(2), 79-97.

[22] Shephard, R.J. (2000). Aging and productivity: some physiological issues. International Journal of Industrial Ergonomics, $25,535-545$.

[23] Ostwald, S. K., and Williams. H. Y. (1985). Optimizing Learning in the Elderly: A Model. Lifelong Learning, 9, 10-13, 27. 
[24]Withnall, A., McGiviney, V. and Soulsby, J. (2004). Older People Learning: Myths and realities. NIACE: Leicester.

[25]Kothiyal, K. \& Tettey, S. (2000). Anthropometric data of elderly people in Australia. Applied Ergonomics, 31, 329-332.

[26] Shephard, R.J. (2000). Worksite health promotion and the older worker. International Journal of Industrial Ergonomics $25,465-475$

[27]Pinto, M.R., De Medici, S., Van Sant, C., Bianchi, A., Zlotnicki, A., and Napoli, C. (2000). Ergonomics, gerontechnol- ogy, and design for the home-environment, Applied Ergonomics, 31, 317-322.

[28]Demirbileka, O. \& Demirkan, H. (2004). Universal product design involving elderly users: a participatory design model, Applied Ergonomics, 35, 361-370.

[29] Kowalski-Trakofler, K.M., Steiner, L. J. And Schwerha, D. J. (2005). Safety considerations for the aging workforce, Safety Science, 43, 779-793. 